\title{
EDITORIAL
}

\section{ZOOLOGIA 30 years: commemorative edition}

According to the lyrics of a famous Brazilian song, one should never trust a person who is older than 30 . Well, this saying does not apply to our journal. Thirty years ago, the Revista Brasileira de Zoologia was born thanks to the idealism of a few zoologists. It has since become the official publication of the Brazilian Society of Zoology.

During all these years, ZOOLOGIA, as the publication is called today, has been closely linked to the history of zoology in Brazil, representing an important source of publications on a significant portion all studies on the Neotropical fauna worldwide. It is an important vehicle for established scientists from all over the world to communicate their ideas, and also provides a friendly environment where young zoologists can publish their first scientific contributions.

The science of zoology in today's Brazil is exciting and productive, and we believe that both ZOOLOGIA and the Brazilian Society of Zoology bear some responsibility in it. The work and dedication of past and present editors, presidents of the SBZ, and the contributions of important zoologists have promoted the present international recognition of ZOOLOGIA. ZOOLOGIA today, continues to represent the most traditional and recognized zoology journal in Brazil, with a significant reputation among the international community in the area.

The editorial policy of ZOOLOGIA has been to publish quality manuscripts, regardless sub-area. We are aware of the scientometric parameters used in the present days but we also recognize that quality is far more important than quantity. Thus, the path we have chosen for ZOOLOGIA does not leave place for the artificial manipulation of manuscripts to achieve higher comparative scientometric parameters.

We know what quality is, and we know who we are. Thus, we ask you to trust ZOOLOGIA, despite the fact that it is now 30 years old! We will continue providing the best service to get your research published efficiently!

Walter A.P. Boeger \& Sionei R. Bonatto

Editors of Zoologia 